Тинина Людмила Павловна, доцент, Ангарский государственный технический университет, e-mail: tinina-Ip@inbox.ru

Коновалов Юрий Васильевич, к.т.н., доцент, Ангарский государственный технический университет, e-mail: yrvaskon@mail.ru

Истратов Роман Сергеевич, обучающийся, Ангарский государственный технический университет

Величко Максим Александрович, обучающийся, Ангарский государственный технический университет

МЕТОДИКА РАСЧЕТА УТОЧНЕННЫХ ХАРАКТЕРИСТИК ТРАНСФОРМАТОРОВ ТОКА ДЛЯ ПОВЫШЕНИЯ ЭФФЕКТИВНОСТИ РАБОТЫ УСТРОЙСТВ РЕЛЕЙНОЙ ЗАЩИТЫ

Tinina L.P., Konovalov Yu.V., Istratov R.S., Velichko M.A.

\title{
METHOD FOR CALCULATING THE REFINED CHARACTERISTICS OF CURRENT TRANSFORMERS TO INCREASE THE EFFICIENCY OF RELAY PROTECTION DEVICES
}

\begin{abstract}
Аннотация. Создана методика выбора технических характеристик трансформаторов тока и подключенных устройств релейной защиты, обеспечивающих надежность системы электроснабжения в соответствии с современными требованиями.

Ключевые слова: трансформаторы тока, переходный режим, время насыщения, апериодическая составляющая, таблично-графический метод, визуализация.

Abstract. A method has been developed for selecting the technical characteristics of current transformers and connected relay protection devices that ensure the reliability of the power supply system in accordance with modern requirements.
\end{abstract}

Keywords: current transformers, transient mode, saturation time, current, aperiodic component, tabular-graphical method, visualization.

C выходом нового предварительного национального стандарта ПНСТ 283 - 2018 «Трансформаторы измерительные. Часть 2 Технические условия на трансформаторы тока» [1] и ГОСТ Р58669 - 2019 «Единая энергетическая система и изолированно работающие энергосистемы. Релейная защита. Трансформаторы тока измерительные индуктивные с замкнутым магнитопроводом для защиты. Методические указания по определению времени до насыщения при коротких замыканиях» [2], появилась необходимость проведения расчетов уточненных характеристик трансформаторов тока (ТT). Данные требования связаны с накоплением магнитного потока в магнитопроводе ТТ, ввиду отсутствия или малости тока обратной полярности. Это явление вызывает избыточную (неправильную) работу устройств Р3, что может привести к крупным авариям с отключением большого числа потребителей электроэнергии.

Новые нормативные документы предусматривают выполнение предварительных расчетов времени до насыщения трансформаторов тока для быстродействующих устройств релейной защиты (Р3) при строительстве и комплекс- 
ном перевооружении объектов энергетики на этапе проектной документации [3]. Алгоритм, обеспечивающий правильное функционирование устройств Р3 при котором обеспечивается отключение короткого замыкания (КЗ) за время меньшее, чем рассчитанное время до насыщения ТТ, приведен в таблице 1.

Таблица 1

Алгоритм расчета

\begin{tabular}{|c|c|}
\hline Величина & Расчетная фрормула с пояснениями \\
\hline $\begin{array}{l}\text { Сопротивление фазы про- } \\
\text { вода в токовых цепях }\end{array}$ & $\begin{array}{l}\qquad R_{\text {пр }}=\frac{\rho \cdot l}{S} \\
\text { где } \rho-\text { удельная проводимость меди, } \frac{\text { ом'мм }}{\text { м }} ; \\
l-\text { длина токовых цепей, м; } \\
S-\text { сечение кабеля, мм². }\end{array}$ \\
\hline $\begin{array}{l}\text { Сопротивление фазы уст- } \\
\text { ройства Р3 включенного в } \\
\text { токовые цепи }\end{array}$ & $\begin{array}{l}z_{\mathrm{p \phi}}=\frac{S_{\text {уст }}}{I_{2 \text { ном }}^{2}} \\
\text { где } S_{\text {уст }}-\text { потребляемая мощность устройства Р3 на } \\
\text { фазу, ВА; } \\
I_{2 \text { ном }}-\text { номинальный вторичный ток, А. }\end{array}$ \\
\hline Номинальная нагрузка ТТ & $Z_{\text {н.ном }}=\frac{S_{\text {ном }}}{I_{2 \mathrm{HOM}}^{2}}$ \\
\hline $\begin{array}{l}\text { Сопротивление вторичной } \\
\text { нагрузки с учётом микро- } \\
\text { процессорных устройств и } \\
\text { схемы соединения вто- } \\
\text { ричных обмоток ТТ в } \\
\text { «звезду» при трехфазном } \\
\text { КЗ }\end{array}$ & $\begin{array}{c}R_{\text {Н.факт }}=\sum R_{\text {пр }} \\
X_{\text {н.факт }}=Z_{\text {рф }}\end{array}$ \\
\hline $\begin{array}{l}\text { Сопротивление вторичной } \\
\text { нагрузки с учётом микро- } \\
\text { процессорных устройств и } \\
\text { схемы соединения вто- } \\
\text { ричных обмоток ТТ в } \\
\text { «зезду» при однофразном } \\
\text { КЗ }\end{array}$ & $\begin{array}{c}R_{\text {н.факт }}=2 \sum R_{\text {пр }} \\
X_{\text {н.факт }}=Z_{\mathrm{p} \phi}+Z_{\mathrm{p} 0}\end{array}$ \\
\hline $\begin{array}{l}\text { Полное сопротивление } \\
\text { ветви вторичного тока }\end{array}$ & $\begin{array}{l}Z_{2 \Sigma \text { ном }} \\
=\sqrt{\left(R_{2}+Z_{\text {н.ном }} \cdot \cos \varphi_{\text {н.ном }}\right)^{2}+\left(X_{2}+z_{\text {н.ном }} \cdot \sin \varphi_{\text {н.ном }}\right)^{2}} \\
\text { где } R_{2}-\text { активное сопротивление вторичной обмот- } \\
\text { киТТ; } \\
X_{2}-\text { реактивное сопротивление вторичной обмотки } \\
\text { ТT; } \\
Z_{\text {н.ном }}-\text { номинальная нагрузка ТТ; } \\
\varphi_{\text {н.ном }}-\text { номинальное значение угла сопротивления } \\
\text { нагрузки ТТ. }\end{array}$ \\
\hline
\end{tabular}


Таблица 1 (окончание)

\begin{tabular}{|c|c|}
\hline Величина & Расчетная формула с пояснениями \\
\hline $\begin{array}{l}\text { Полное сопротивление } \\
\text { ветви вторичного тока при } \\
\text { КЗ }\end{array}$ & $\begin{array}{l}\qquad z_{2 \Sigma}=\sqrt{\left(R_{2}+R_{\text {н.факт }}\right)^{2}+\left(X_{2}+X_{\text {н.факт }}\right)^{2}} \\
\text { где } R_{\text {н.факт }}-\text { фактическое активное сопротивление } \\
\text { нагрузки ТТ; } \\
X_{\text {н.факт }}-\text { фрактическое реактивное сопротивление на- } \\
\text { грузки ТТ. }\end{array}$ \\
\hline $\begin{array}{l}\text { Параметр режима А при } \\
\text { К3 }\end{array}$ & 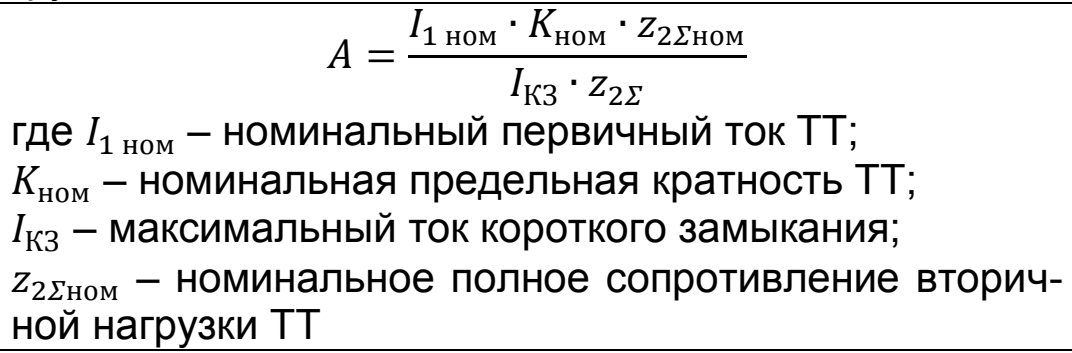 \\
\hline $\begin{array}{l}\text { Время насыщения ТТ при } \\
\text { отсутствии остаточной на- } \\
\text { магниченности сердечника } \\
\text { при КЗ }\end{array}$ & $t_{\text {нас }}=T_{\text {р.экв }} \cdot \ln \frac{\omega \cdot T_{\text {р.экв }}}{\omega \cdot T_{\text {р.экв }}-A+1}$ \\
\hline $\begin{array}{l}\text { Время насыщения ТТ при } \\
\text { наличии остаточной на- } \\
\text { магниченности в сердеч- } \\
\text { нике при КЗ }\end{array}$ & $t_{\text {нас }}=T_{\text {р.экв }} \cdot \ln \frac{\omega \cdot T_{\text {р.экв }}}{\omega \cdot T_{\text {р.экв }}-A \cdot\left(1-K_{r}\right)+1}$ \\
\hline $\begin{array}{l}\text { Условие насыщения маг- } \\
\text { нитопровода }\end{array}$ & $\omega \cdot T_{\text {р.экв }}+1>A \cdot\left(1-K_{r}\right)$ \\
\hline
\end{tabular}

Исходные данные для расчета приведены в табл. 2, вариант реализации алгоритма продемонстрирован расчетами в табл. 3.

Таблица 2

Пример расчета

\begin{tabular}{|c|c|c|c|c|c|c|}
\hline \multicolumn{3}{|c|}{ Паспортные данные ТT } & \multicolumn{4}{|c|}{ Параметры провода токовых цепей } \\
\hline Наименование & \multicolumn{2}{|c|}{ TA1 } & Участок №1 & \multicolumn{2}{|c|}{ ТТ- Р3 (медь) } & $R_{\text {пр }}$ \\
\hline $\begin{array}{l}\text { Номинальный } \\
\text { первичный } \\
\text { ток, А }\end{array}$ & $I_{1 \text { ном }}$ & 600 & $\begin{array}{l}\text { Длина токовых } \\
\text { цепей, м }\end{array}$ & $\mathrm{L}$ & 96 & 0,28 \\
\hline $\begin{array}{l}\text { Номинальный } \\
\text { вторичный ток, } \\
\text { А }\end{array}$ & $I_{2 \text { ном }}$ & 5 & $\begin{array}{l}\text { Сечение кабе- } \\
\text { ля, } \text { мм }^{2}\end{array}$ & S & 6 & \\
\hline $\begin{array}{l}\text { Номинальная } \\
\text { мощность ТТ, } \\
\text { ВА }\end{array}$ & $S_{\text {ном }}$ & 30 & Участок 2 & & & \\
\hline $\begin{array}{l}\text { Номинальная } \\
\text { нагрузка ТT, } \\
\text { Ом }\end{array}$ & $Z_{2 \text { нагр. }}$ & 1,2 & $\begin{array}{l}\text { Длина токовых } \\
\text { цепей, м }\end{array}$ & $\mathrm{L}$ & 3 & 0,021 \\
\hline $\begin{array}{l}\text { Номинальная } \\
\text { предельная } \\
\text { кратность }\end{array}$ & $K_{\text {ном }}$ & 30 & $\begin{array}{l}\text { Сечение кабе- } \\
\text { ля, } \text { мм }^{2}\end{array}$ & $\mathrm{~S}$ & 2,5 & \\
\hline
\end{tabular}


Таблица 2 (окончание)

\begin{tabular}{|c|c|c|c|c|c|c|}
\hline \multicolumn{3}{|c|}{ Паспортные данные ТТ } & \multicolumn{4}{|c|}{ Параметры провода токовых цепей } \\
\hline $\begin{array}{l}\text { Активное со- } \\
\text { противление } \\
\text { вторичной об- } \\
\text { мотки, Ом }\end{array}$ & $R_{2}$ & 0,4 & \multicolumn{4}{|c|}{ Параметры устройств Р3 } \\
\hline $\begin{array}{l}\text { Реактивное } \\
\text { сопротивление } \\
\text { вторичной об- } \\
\text { мотки, Ом }\end{array}$ & $X_{2}$ & 0,9 & $\begin{array}{l}\text { Реле № } 1 \text { По- } \\
\text { требляемая } \\
\text { мощность на } \\
\text { фазу, ВА }\end{array}$ & $S_{\text {уст. }}$ & \multirow[t]{2}{*}{ P642 } & 2,5 \\
\hline \multirow[t]{2}{*}{$\begin{array}{l}\text { Коэфффициент } \\
\text { мощности на- } \\
\text { грузки }\end{array}$} & $\cos \varphi_{\mathrm{H}}$ & 0,8 & $\begin{array}{l}\text { сопротивление } \\
\text { фазы устрой- } \\
\text { ства, Ом }\end{array}$ & $Z_{\mathrm{p} . \phi}$ & & 0,1 \\
\hline & $\sin _{\varphi_{\mathrm{H}}}$ & 0,6 & $\begin{array}{l}\text { Реле № } 2 \text { по- } \\
\text { требляемая } \\
\text { мощность на } \\
\text { фазу, ВА }\end{array}$ & $S_{\text {уст. }}$ & \multirow[t]{2}{*}{ P143 } & 0,15 \\
\hline $\begin{array}{l}\text { Полная по- } \\
\text { грешность } \\
\text { ТТ,в \% }\end{array}$ & $\varepsilon$ & 10 & $\begin{array}{l}\text { сопротивление } \\
\text { фазы устрой- } \\
\text { ства, Ом }\end{array}$ & $Z_{\mathrm{p} . \phi}$ & & 0,006 \\
\hline $\begin{array}{l}\text { Схема соеди- } \\
\text { нения вторич- } \\
\text { ных обмоток } \\
\text { TТ }\end{array}$ & Звезда & & $\begin{array}{l}\text { Реле № } 3 \text { по- } \\
\text { требляемая } \\
\text { мощность на } \\
\text { фазу, ВА }\end{array}$ & $S_{\text {уст. }}$ & - & 0 \\
\hline $\begin{array}{l}\text { Количество } \\
\text { вторичных об- } \\
\text { моток для Р3 }\end{array}$ & 1 & & $\begin{array}{l}\text { Сопротивление } \\
\text { фазы устрой- } \\
\text { ства, Ом }\end{array}$ & $Z_{\mathrm{p} . \phi}$ & - & 0 \\
\hline
\end{tabular}

Таблица 3

Пример расчета

\begin{tabular}{|c|c|c|}
\hline Наименование величины & $\begin{array}{c}\text { при трехфазном корот- } \\
\text { ком замыкании }\end{array}$ & $\begin{array}{c}\text { при однофразном коротком } \\
\text { замыкании }\end{array}$ \\
\hline Максимальный ток КЗ,А & 6100 & 4600 \\
\hline $\begin{array}{l}\text { Эквивалентная постоянная } \\
\text { времени затухания } T_{\text {р.экв }} \text {, сек }\end{array}$ & 0,02 & 0,014 \\
\hline $\begin{array}{l}\text { Фактическое сопротивление } \\
\text { нагрузки } R_{\text {н.факт }}=R_{\text {пр} \Sigma}\end{array}$ & 301 & \\
\hline $\begin{array}{l}\text { Фактическое сопротивление } \\
\text { нагрузки }\end{array}$ & & 602 \\
\hline $\begin{array}{l}R_{\text {н.факт }}=2 R_{\text {пр} \Sigma} \text { при однофаз- } \\
\text { ном коротком замыкании }\end{array}$ & & \\
\hline $\begin{array}{l}\text { Фактическое сопротивление } \\
\text { нагрузки } X_{\text {н.факт }}=Z_{\text {р.ф } \Sigma} \text { при } \\
\text { трехфазном коротком замы- } \\
\left.\text { кании } X_{\text {н.факт }}=Z_{\text {p.ф. }}+Z_{\text {ро }}\right), 0 \text { Мм } \\
\text { при однофразном коротком за- } \\
\text { мыкании }\end{array}$ & 0,1 & 0,1 \\
\hline $\begin{array}{l}\text { Номинальное полное сопро- } \\
\text { тивление вторичной нагрузки } \\
\text { TT } Z_{2 \Sigma \text { ном }}, 0 \text { м }\end{array}$ & 2,115 & 2,115 \\
\hline
\end{tabular}


Таблица 3 (окончание)

\begin{tabular}{|c|c|c|}
\hline Наименование величины & $\begin{array}{c}\text { при трехфазном корот- } \\
\text { ком замыкании }\end{array}$ & $\begin{array}{c}\text { при однофразном коротком } \\
\text { замыкании } \\
\end{array}$ \\
\hline $\begin{array}{l}\text { Полное сопротивление ветви } \\
\text { вторичного тока } Z_{2 \Sigma} \text {, Ом }\end{array}$ & 1,221 & 1,416 \\
\hline Параметр режима A & 5,111 & 5,847 \\
\hline \multicolumn{3}{|c|}{ Определение времени без остаточного намагничивания } \\
\hline $\begin{array}{l}\text { Остаточная намагниченность } \\
K_{r}\end{array}$ & 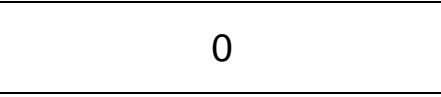 & 0 \\
\hline $\begin{array}{l}\text { Проверка условия } \\
\omega \times T_{\text {р.экв }}+1>\mathrm{A} \cdot\left(1-K_{r}\right) \text { ec- } \\
\text { ли условие }\end{array}$ & Условие выполняется & Условие выполняется \\
\hline $\begin{array}{l}\text { Проверка условия } \\
A \cdot\left(1-K_{r}\right)>1 \text { невыполнение } \\
\text { означает, что эксплуатация } \\
\text { TТ недопустима }\end{array}$ & Условие выполняется & $\begin{array}{c}\text { Магнитопровод не насы- } \\
\text { щается }\end{array}$ \\
\hline Время насыщения $t_{\text {нас }}$, сек & 0,0213 & Равно бесконечности \\
\hline \multicolumn{3}{|c|}{ Определение времени с остаточным намагничиванием } \\
\hline $\begin{array}{l}\text { Остаточная намагниченность } \\
K_{r}\end{array}$ & 0,86 & 0,86 \\
\hline $\begin{array}{l}\text { Проверка условия } \\
\omega \times T_{\text {р.экв }}+1>\mathrm{A} \cdot\left(1-K_{r}\right) \text { ec- } \\
\text { ли условие }\end{array}$ & Условие выполняется & Условие выполняется \\
\hline $\begin{array}{l}\text { Проверка условия } \\
\text { А · }\left(1-K_{r}\right)>1 \text { невыполне- } \\
\text { ние означает, что } t_{\text {нас }} \text { прини- } \\
\text { мает отрицательное значение } \\
\text { и необходим расчёт графиче- } \\
\text { ским методом }\end{array}$ & $\begin{array}{l}\text { Необходим расчёт } \\
\text { графическим методом }\end{array}$ & $\begin{array}{c}\text { Необходим расчёт графри- } \\
\text { ческим методом }\end{array}$ \\
\hline Время насыщения $t_{\text {нас }}$, сек & $-0,0009$ & $-0,0006$ \\
\hline $\begin{array}{l}\text { Время насыщения по графи- } \\
\text { ческому методу } t_{\text {нас, }} \text { сек }\end{array}$ & 0,0045 & 0,0053 \\
\hline
\end{tabular}

Эксплуатируемые в настоящее время ТТ класса 10Р имеют в сердечнике остаточную магнитную индукцию, достигающую 86\%. Поэтому в соответствии с ГОСТом [2] коэффрициент остаточной намагниченности сердечника ТТ $\mathrm{K}_{\mathrm{r}}$ необходимо принимать равным 0,86. В ходе расчёта при невыполнении условия $\mathrm{A} \cdot\left(1-\mathrm{K}_{\mathrm{r}}\right)>1$ время насыщения $\mathrm{t}_{\text {нас }}$ ТТ принимает отрицательное значение и возникает необходимость расчёта графическим методом, для его осуществления требуется построить график функции коэффициента переходного режима $\mathrm{K}_{\text {п.р }}(\mathrm{t})$. При активно-индуктивном характере сопротивления вторичной цепи ТT:

$$
\mathrm{K}_{\text {п. }}(\mathrm{t})=\sin \alpha \cdot \mathrm{e}^{-\frac{\mathrm{t}}{\mathrm{T}_{\mathrm{p}}}}+\cos \alpha \cdot \omega \cdot \mathrm{T}_{\mathrm{p}}\left(1-\mathrm{e}^{-\frac{\mathrm{t}}{\mathrm{T}_{\mathrm{p}}}}\right)-\sin (\omega \cdot \mathrm{t}+\alpha)
$$

активном характере сопротивления вторичной цепи ТТ: 


$$
\mathrm{K}_{\text {п. }}(\mathrm{t})=\omega \cdot \mathrm{T}_{\mathrm{p}}\left(1-\mathrm{e}^{-\frac{\mathrm{t}}{\mathrm{T}_{\mathrm{p}}}}\right)-\sin (\omega \mathrm{t})
$$

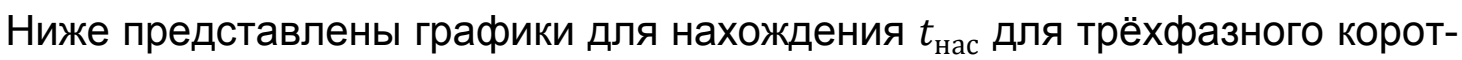
кого замыкания - рисунок 1 , и для однофазного короткого замыкания - рисунок 2.

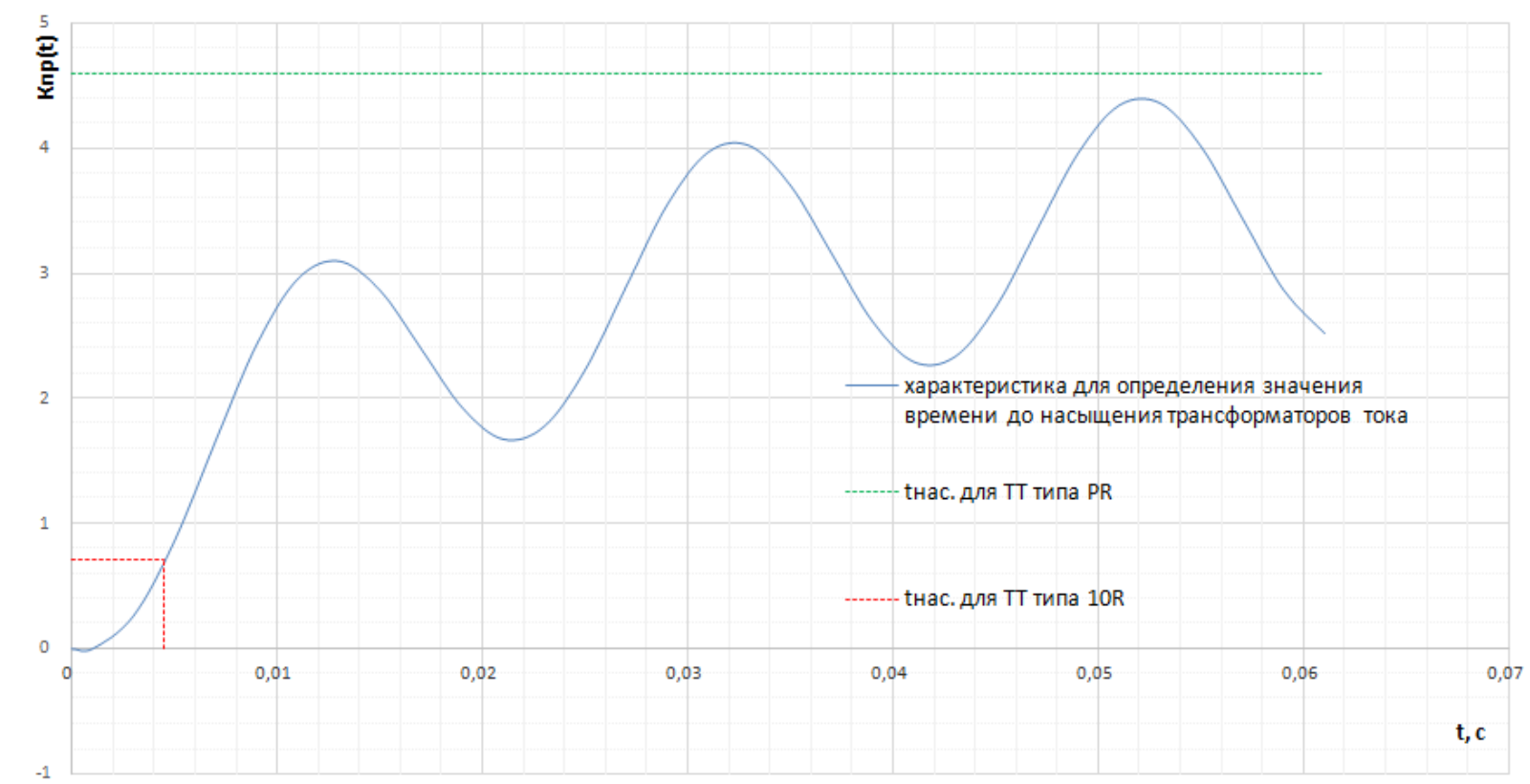

Рисунок 1 - График для ТТ с Тр. экв = 0,02 с

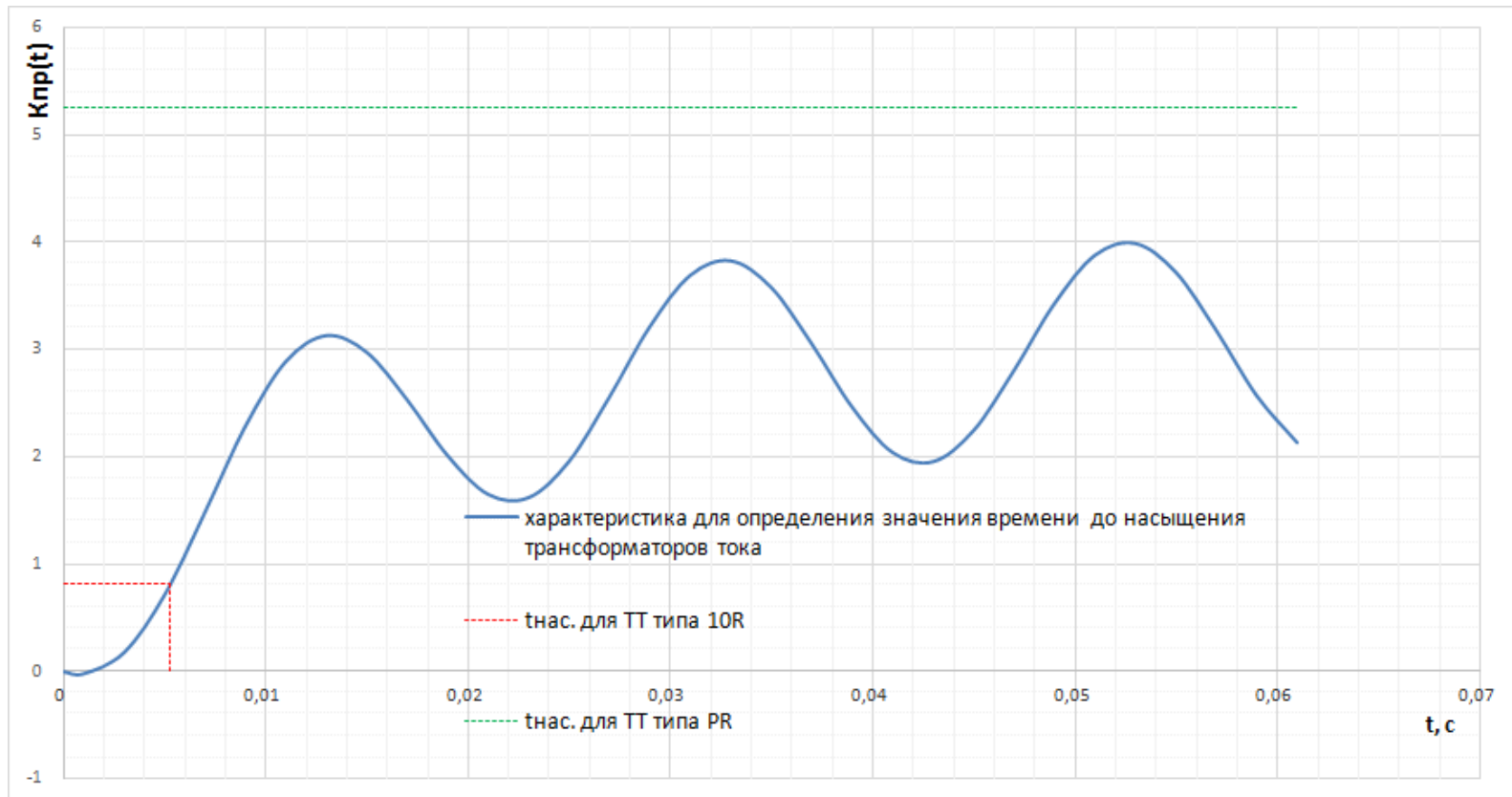

Рисунок 2 - График для ТТ с $\mathrm{T}_{\text {р.экв }}=0,018$ с

Для нахождения времени насыщения $\mathrm{t}_{\text {нас }}$ на рисунках 1 и 2 необходимо значение $\mathrm{A} \cdot\left(1-\mathrm{K}_{\mathrm{r}}\right)$ отложить по оси ординат и на пересечении с графиком $\mathrm{K}_{\text {п.р }}(\mathrm{t})$ по оси абсцисс определим искомое значение времени. 
Также на рисунке 2 показано значение A $\left(1-\mathrm{K}_{\mathrm{r}}\right)$ для TT класса PR c нормируемой остаточной намагниченностью достигающую $10 \%$. В таком случае

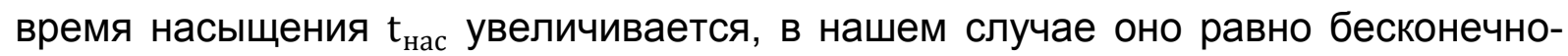
сти, соответственно, не превышает время срабатывания релейной защиты, что соответствует всем требованиям. TT класса PR могут быть установлены на место действующих транссорматоров.

Продемонстрированный расчёт, выполненный с использованием программного пакета Excel, показал удобство и простоту нахождения всех необходимых данных для выбора технических характеристик ТТ и подключенных устройств Р3 на предмет соответствия последнему ГОСТ Р58669 - 2019. Данный метод позволяет значительно упростить и ускорить процесс выбора, минимизировать ошибки, опираясь на таблично-графическую визуализацию. Благодаря самостоятельно построенной характеристике апериодической составляющей с использованием коэффрициента переходного режима Кп.р.(t), нахождение времени насыщения ТТ значительно упрощается. Математические выражения, кривые, определяющие содержание апериодической составляющей в первичном токе, достаточно единожды представить в программе Excel. Табличный вариант позволяет наглядно видеть изменение в расчетах при изменении входных величин и может быть шаблоном при выполнении расчетов как проектными, так и энергоснабжающими организациями.

\section{ЛИТЕРАТУРА}

1. ПНСТ 283-2018. Предварительный национальный стандарте РФ «Транссорматоры измерительные. Часть 2. Технические условия на трансформаторы тока» Москва. Стандартинформ, 2018. [Электронный ресурc]. URL: https://docs.cntd.ru/document/1200161312 (обращение 09.03.2021).

2. ГОСТ Р58669-2019 «Единая энергетическая система и изолированно работающие энергосистемы. Релейная защита. Трансформаторы тока измерительные индуктивные с замкнутым магнитопроводом для защиты. Методические указания по определению времени до насыщения при коротких замыканияХ».2007-2021, ФГУП. СТАНДАРТИНФОРМ. [Электронный ресурc]. URL: http:// protect.gost.ru/document.aspx?control=7\&id=238273 (обращение 09.03.2021).

3. Королев Е.П., Либерзон Э.М. Расчеты допустимых нагрузок в токовых цепях релейной защиты. - М.: Энергия,1980. - 208 с. 